\title{
EFEITO DO ÁCIDO ZOLEDRÔNICO EM TÍBIAS DE RATAS OOFORECTOMIZADAS. ESTUDO PROSPECTIVO E RANDOMIZADO.
}

\author{
EFFECTS OF ZOLEDRONIC ACID ON OOFORECTOMIZED \\ RATS' TIBIAE: A PROSPECTIVE AND RANDOMIZED STUDY
}

\author{
Fernando Roberto Alves Pereira ${ }^{1}$ \\ Ricardo César Dutra ${ }^{1}$ \\ Thiago César Reis Olímpio' \\ Sérgio Swain Müller² \\ Evandro Pereira Palacio 3
}

\section{RESUMO}

Objetivo: Investigar as repercussões clínicas, biomecânicas e histomorfométricas do ácido zoledrônico em tíbias de ratas osteoporóticas, após ooforectomia bilateral. Métodos: Foram estudadas, prospectivamente, 40 ratas da linhagem Wistar (Rattus novergicus albinus). Com 60 dias de vida, os animais foram aleatorizados em dois grupos de acordo com o procedimento cirúrgico: ooforectomia bilateral $(\mathrm{O})(\mathrm{n}=20)$ e pseudo-cirurgia ("sham") $(\mathrm{P})(\mathrm{n}=20)$. Após 30 dias, os animais foram divididos em quatro subgrupos, de acordo com a administração de $0,1 \mathrm{mg} / \mathrm{kg}$ de ácido zoledrônico (AZ) ou água destilada $(\mathrm{AD})$ : OAZ $(\mathrm{n}=10), \mathrm{OAD}(\mathrm{n}=10), \mathrm{PAZ}(\mathrm{n}=10)$ e PAD $(n=10)$. Após 12 meses, os animais foram eutanasiados e suas tíbias analisadas. No estudo clínico foi considerado o peso dos animais; no estudo biomecânico foram realizados ensaios compressivos e na análise histomorfométrica foi determinada a área trabecular óssea. Resultados: Os grupos "O" tiveram aumento de peso significativamente maior que os grupos "P" $(p=0,005)$. Os grupos OAZ e PAZ tiveram aumento, não significativo, de peso quando comparados aos grupos $\mathrm{OAD}(p=0,47)$ e $\mathrm{PAD}(p=0,68)$. Os grupos com ácido zoledrônico e com água destilada suportaram carga máxima, semelhante $(p=0,2)$, no momento em que ocorreu fratura. Nos grupos com ácido zoledrônico verificou-se o aumento não significante da área trabecular óssea quando comparados aos grupos com água destilada $(p=0,21)$. Houve correlação positiva entre a área trabecular e a carga máxima $(p=0,04 ; \mathrm{r}=0,95)$. Conclusão: $\mathrm{O}$ ácido zoledrônico não influiu significativamente no peso dos animais. Os resultados mostraram aumento, não significante, tanto da resistência óssea diafisária tibial, como da área trabecular óssea.

Descritores - Osteoporose; Biomecânica; Tíbia; Epidemiologia experimental; Ratos Wistar; Estudos prospectivos

\section{ABSTRACT}

Objective: To investigate clinical, biomechanic and histomorphometric effects of zoledronic acid on osteoporotic rats' tibiae after bilateral ooforectomy. Methods: 40 female Wistar (Rattus novergicus albinus) rats were prospectively studied. On the 60th day of life, the animals were randomized into two groups according to the surgical procedure: bilateral ooforectomy $(O)(n=20)$ and sham surgery ("sham") (P) (n=20). After 30 days, the animals were divided into four groups, according to the administration of zoledronic acid (ZA) $0.1 \mathrm{mg} / \mathrm{kg}$ or distilled water (DW): OZA $(n=10), O D W$ $(n=10), P Z A(n=10)$ and PDW $(n=10)$. After 12 months, the animals were sacrificed, and had their tibiae assessed. In the clinical study, animals'weight was considered; in the biomechanical study, compressive assays were applied and, in the histomorphometric analysis, the bone trabecular area was determined. Results: "O" groups showed a significantly greater weight gain than " $P$ " groups $(p=0.005)$. Groups OZA and PZA showed an insignificant weight gain when compared to $O D W(p=0.47)$ and $P D W(p=0.68)$. The groups receiving zoledronic acid and distilled water were able to bear maximum load, similar ( $p=0.2)$, at the moment of fracture. In the groups receiving zoledronic acid, an insignificant increase of the bone trabecular area was found when compared to the groups receiving distilled water $(p=0.21)$. There was a positive correlation between trabecular area and maximum load ( $p=0.04 ; r=0.95$ ). Conclusion: Zoledronic acid did not significantly influence animals' weight. The results showed an insignificant increase both of the tibial shaft bone resistance and the bone trabecular area.

Keywords - Osteoporosis; Biomechanics; Tibia; Experimental epidemiology; Wistar rats; Prospective studies

1 - Médico Residente do Programa de Ortopedia e Traumatologia da Faculdade de Medicina de Marília/Famema - Marília/SP.

2 - Professor Assistente Doutor do Departamento de Cirurgia e Ortopedia da Faculdade de Medicina de Botucatu/Unesp - Botucatu/SP.

3 - Professor Assistente do Departamento de Ortopedia e Traumatologia da Faculdade de Medicina de Marília/Famema - Marília/SP.

Trabalho realizado no Departamento de Cirurgia e Ortopedia da Faculdade de Medicina de Botucatu/UNESP - Botucatu/SP

Correspondência: Dr. Evandro P. Palacio, Faculdade de Medicina de Marília/Famema, Departamento de Ortopedia e Traumatologia, Rua Monte Carmelo, 800 Fragata, CEP 17519-030, Marília/SP, Brasil. E-mail: palacio@famema.br

Declaração: Não houve auxílio, de qualquer espécie, a esta pesquisa e não há conflitos de interesse dos autores em relação ao presente manuscrito, conforme Resolução $\mathrm{n}^{\circ} 1.595 / 2000$ do Conselho Federal de Medicina. 


\section{INTRODUÇÃO}

As transformações tecnológicas ocorridas no Brasil durante o último século, o avanço da medicina e a urbanização, levaram ao aumento da expectativa de vida da população em geral e estão proporcionando o seu envelhecimento $(*)^{(1,2)}$. Mais do que dados demográficos isolados, este aumento significativo da parcela idosa da população exige novos e eficientes investimentos em saúde pública. As doenças crônico-degenerativas tornam-se cada vez mais comuns e, dentre elas, a osteoporose assume papel relevante ${ }^{(3)}$.

Causada, principalmente, pela perda do balanço homeostático do tecido ósseo, a osteoporose é uma doença assintomática. Na maioria dos casos, a doença se manifesta inicialmente pela ocorrência de fraturas, principalmente vertebrais, femorais e da extremidade distal do rádio ${ }^{(4-6)}$.

A prevenção é o tratamento de escolha. Sabe-se que a poupança óssea, realizada durante a mocidade, é um dos fatores primordiais para instalação ou não da osteoporose $^{(5-7)}$. Em alguns casos, a terapia medicamentosa torna-se a medida mais eficaz para reverter ou, mais comumente, impedir o avanço da doença ${ }^{(5,8,9)}$. Existem, atualmente, duas classes principais de medicamentos: os agentes inibidores da reabsorção óssea e os agentes estimuladores de sua formação ${ }^{(8)}$.

Os representantes mais acreditados da classe dos inibidores da reabsorção óssea são os bisfosfonatos, que, bloqueando a atividade osteoclástica, são especialmente úteis nas doenças que se manifestam por rápida remodelação óssea ${ }^{(10,11)}$. Dentre os medicamentos desta classe terapêutica, os chamados amino-bisfosfonatos, ou bisfosfonatos de $3^{\mathrm{a}}$ geração, são até 10 mil vezes mais potentes que os bisfosfonatos mais conhecidas ${ }^{(12-14)}$.

O ácido zoledrônico (zoledronato), um novo bisfosfonato, na dose de $5 \mathrm{mg}$ ao ano, em infusão endovenosa, é indicado como capaz de diminuir os efeitos colaterais decorrentes do uso diário desta classe farmacológica, bem como eliminar a baixa adesão dos pacientes ao tratamento ${ }^{(15,16)}$.

As poucas publicações existentes relacionam o ácido zoledrônico à prevenção de fraturas por osteoporose em coluna vertebral e no segmento proximal do fêmur ${ }^{(17-19)}$. O objetivo deste estudo foi avaliar, por meio de estudos clínicos, biomecânicos e histomorfométricos, o efeito do ácido zoledrônico, em dose única anual, sobre a diáfise tibial de ratas ooforectomizadas.

\section{MÉTODOS}

Todos os procedimentos foram aprovados pela Comissão de Ética em Experimentação Animal da Faculdade de Medicina de Botucatu/SP, sob o $n^{\circ} 622 / 2007$. Foram utilizadas 40 ratas (Rattus novergicus albinus), linhagem Wistar, sexualmente maduras e virgens, procedentes do Biotério Central da Universidade Estadual Paulista "Júlio de Mesquita Filho" (UNESP) - Campus de Botucatu.

Os animais, depois de avaliados clinicamente e pesados, foram alojados em grupos de cinco, em oito gaiolas de polipropileno com tampa de grade de metal e forradas com maravalha de pinho autoclavada. Estas eram limpas diariamente e mantidas em local seco e arejado, com temperatura ambiente controlada em $24^{\circ} \mathrm{C}$ e ciclo de luz claro/escuro de 12 horas. Foi oferecida aos animais ração para roedores $\left(\right.$ Labina $^{\circledR}{ }^{\circledR}$, Nestlé Purina PetCare Company $\left.^{(}\right)$e água ad libitum.

Aos 60 dias de vida, após atingirem a maturidade sexual, foram identificados, por perfurações na região auricular direita e esquerda, e aleatorizados, pelo método de sorteio de envelopes opacos lacrados, em dois grupos de acordo com o procedimento cirúrgico a que seriam submetidos: grupo ooforectomia $(\mathrm{O})(\mathrm{n}=20)$ e grupo pseudo-cirurgia ("sham") $(\mathrm{P})(\mathrm{n}=20)$.

O procedimento de castração foi realizado após anestesia, intraperitoneal, com $30 \mathrm{mg} / \mathrm{kg}$ de pentobarbital sódico 3\% e tricotomia, bilateral, logo abaixo da última costela, dorso-lateralmente. Foram submetidos à assepsia com água e sabão, antissepsia com polivinilpirrolidona-iodo tintura (PVPI-tintura) e posicionados em mesa cirúrgica, em decúbito lateral. Após a colocação de campo estéril ocular, foi realizada incisão transversal na pele de aproximadamente $1,5 \mathrm{~cm}$ de comprimento, entre a última costela e a articulação coxofemoral. Com auxílio de pinça, a cavidade peritoneal foi exposta, ultrapassando o plano muscular por divulsão, permitindo acesso ao ovário envolto em tecido adiposo (figura 1).

Procedeu-se à ligadura do ovário com fio de algodão 3.0 e secção do mesmo distalmente à ligadura. A musculatura e a pele foram aproximadas com fio de nylon 4.0 , repetindo-se os mesmos procedimentos no lado contralateral para retirada do outro ovário. Os animais do grupo $\mathrm{P}$ foram submetidos aos mesmos procedimentos cirúrgicos descritos, com exceção do tempo cirúrgico de ligadura e secção dos ovários.

1. (*) IBGE - Instituto Brasileiro de Geografia e Estatística. Projeção da população do Brasil. O Brasil já tem mais de 180 milhões de habitantes. [Comunicação social de 30 de agosto de 2004]. IBGE 2004. 


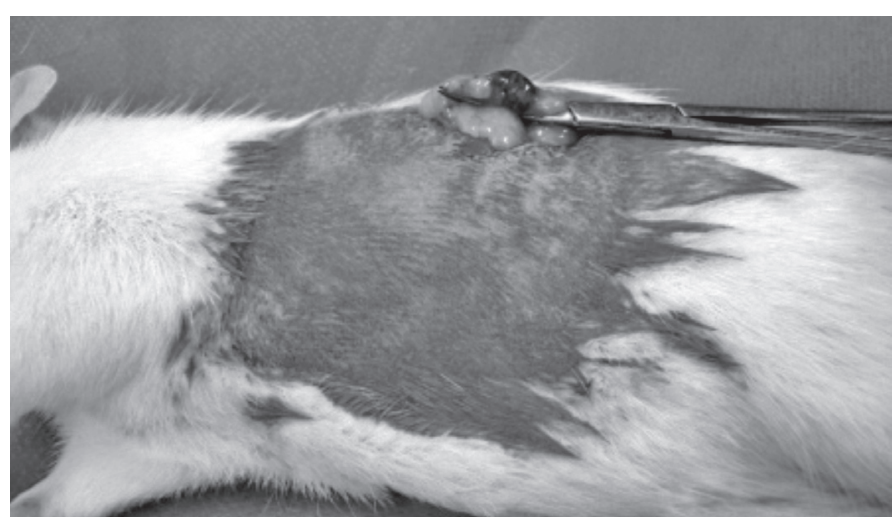

Figura 1 - Aspecto do pinçamento do ovário em meio ao tecido adiposo antes de sua ligadura e secção.

Aos 90 dias de vida e após nova aleatorização, os grupos "O" e "P", foram subdivididos em quatro subgrupos de acordo com a administração, intraperitoneal, na dose recomendada de $0,1 \mathrm{mg} / \mathrm{kg}^{(17,20)}$ de ácido zoledrônico (AZ) $\left(\right.$ Aclasta $^{\mathrm{TM}}$, Novartis ${ }^{\circledR}$ Biociências S.A.) ou água destilada (AD), assim distribuidos: OAZ ( $\mathrm{n}=10)$, OAD $(\mathrm{n}=10), \operatorname{PAZ}(\mathrm{n}=10)$ e PAD $(\mathrm{n}=10)$. Para administração das substâncias utilizou-se seringa estéril para insulina, com agulha fixa, marca Injex Stilly Line ${ }^{\circledR}(1 \mathrm{ml} / \mathrm{cc}$, agulha $12,7 \mathrm{~mm} \times 0,30-30 \mathrm{G} 1 / 2$ ").

Decorridos 12 meses após a administração do ácido zoledrônico ou de água destilada, os animais foram eutanasiados, com dose letal, intraperitoneal, de $80 \mathrm{mg} / \mathrm{kg}$ de pentobarbital sódico 3\%.

Após a eutanásia, as tíbias dos animais foram desarticuladas na região proximal (joelho) e distal (tornozelo), com a retirada das partes moles (músculos, tendões e ligamentos). Para o ensaio biomecânico, as tíbias direitas foram embaladas em papel alumínio, identificadas e congeladas por 24 horas, em refrigerador doméstico, à temperatura de $-20^{\circ} \mathrm{C}$. As tíbias esquerdas foram acondicionadas em recipientes de vidro, limpos e devidamente identificados, e fixadas em solução de formaldeído $10 \%$, para a realização do estudo histomorfométrico.

Estudo clínico: foi realizado pela análise da massa corpórea dos animais (g). As medições foram feitas mensalmente e sempre no mesmo dia, durante todo o experimento, utilizando-se balança digital com capacidade de seis quilogramas-força e variação de $5 \mathrm{~g}$. A aferição da balança era realizada trimestralmente por pessoal técnico.

Estudo biomecânico: para determinação das propriedades mecânicas das tíbias, foram realizados ensaios de flexão em três pontos, utilizando-se a Máquina Universal de Ensaios Mecânicos EMIC ${ }^{\circledR}$, modelo DL 10.000 , com precisão de $(0,018+\mathrm{F} / 3700) \mathrm{KN}$, apurada dentro das especificações das normas ABTN, NBR6156 e NBR6674. A máquina opera em conjunto com computador sob o sistema operacional Windows ${ }^{\mathrm{TM}} 2000$, sob o qual se utilizou o programa Mtest versão 1.00 para aferição dos resultados. Nas 12 horas antes do ensaio biomecânico, as tíbias direitas foram descongeladas e mantidas em compressas embebidas em soro fisiológico $0,9 \%$. Os ossos foram apoiados, horizontal e individualmente, em suas extremidades, sobre dois blocos de madeira. A distância entre os dois pontos de apoio foi padronizada em $2 / 3$ do comprimento do corpo de prova. $\mathrm{O}$ cutelo foi posicionado em ponto eqüidistante às extremidades, na face côncava das tíbias (Figura 2). Para determinação da carga máxima suportada pelo corpo, o cutelo foi posto em movimento a uma velocidade de $30 \mathrm{~mm} / \mathrm{min}^{(21,22)}$. O cálculo da carga máxima foi realizado automaticamente pelo programa (Gráfico 1).

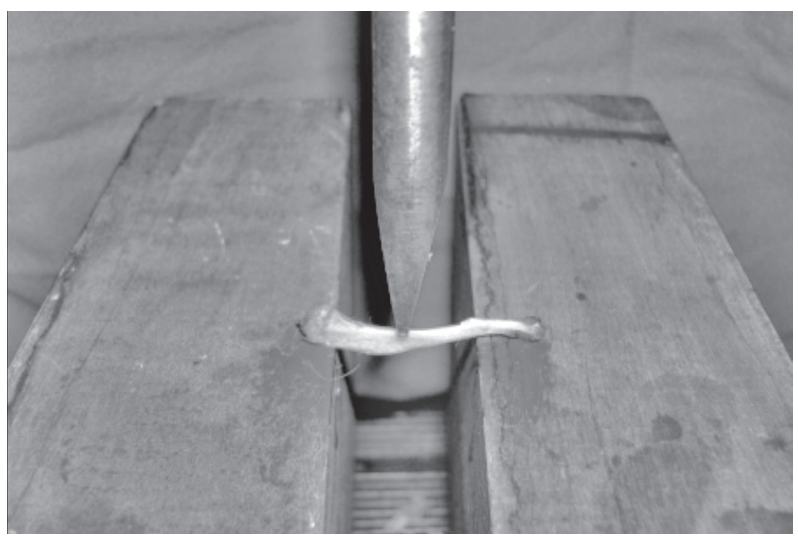

Figura 2 - Detalhe do corpo de prova em repouso e do cutelo de aplicação de carga posicionado em ponto eqüidistante às extremidades.

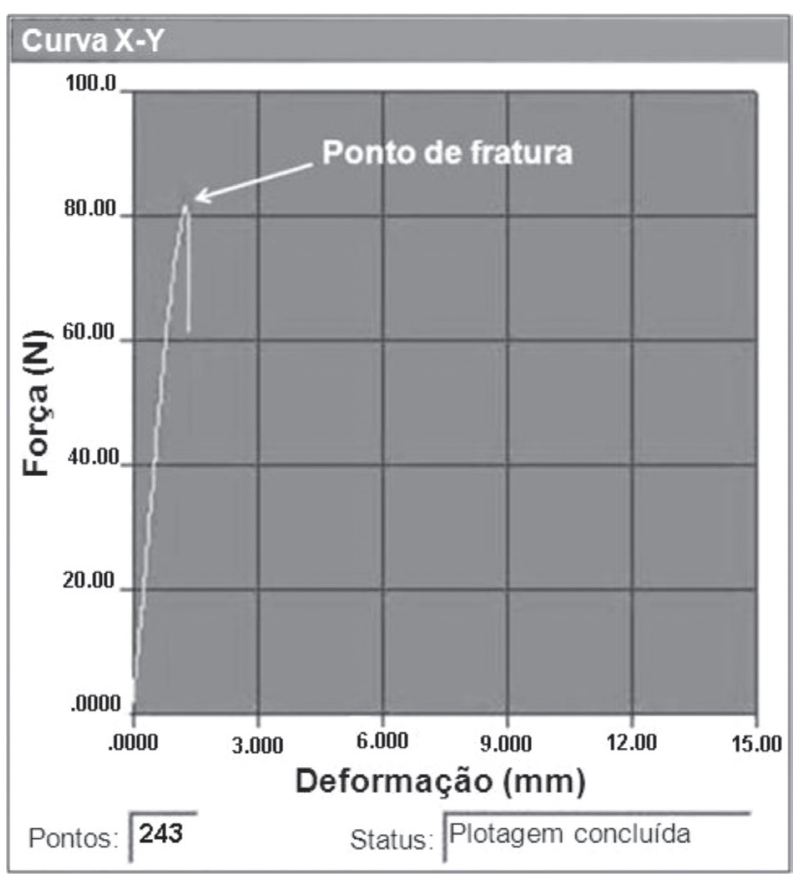

Gráfico 1 - Diagrama carga-deformação obtido durante o ensaio de flexão. 
Estudo histomorfométrico: as tíbias esquerdas, após descalcificação, desidratação, diafanização e inclusão em parafina, foram cortadas transversalmente no terço médio e coradas por hematoxilina-eosina $(\mathrm{HE})^{(23)}$. As lâminas foram colocadas em microscópio $\left(\right.$ Laica $\left.^{\circledR}\right)$ acoplado a monitor de vídeo com resolução de $1024 \times 768$ pixels, que enviava as imagens digitais a um computador. A área de osso trabecular $\left(\mu \mathrm{m}^{2}\right)$ foi calculada utilizando-se a objetiva de $5 \mathrm{X}$ e o programa de análise de imagens Image Pro plus ${ }^{\circledR}$ (Media Cybernetics, Silver Spring, Maryland, USA), em dois campos padrões da região central da diáfise tibial, após delimitação manual do perímetro das trabéculas (Figura 3). O cálculo da área total foi realizado automaticamente pelo programa ${ }^{(24)}$.

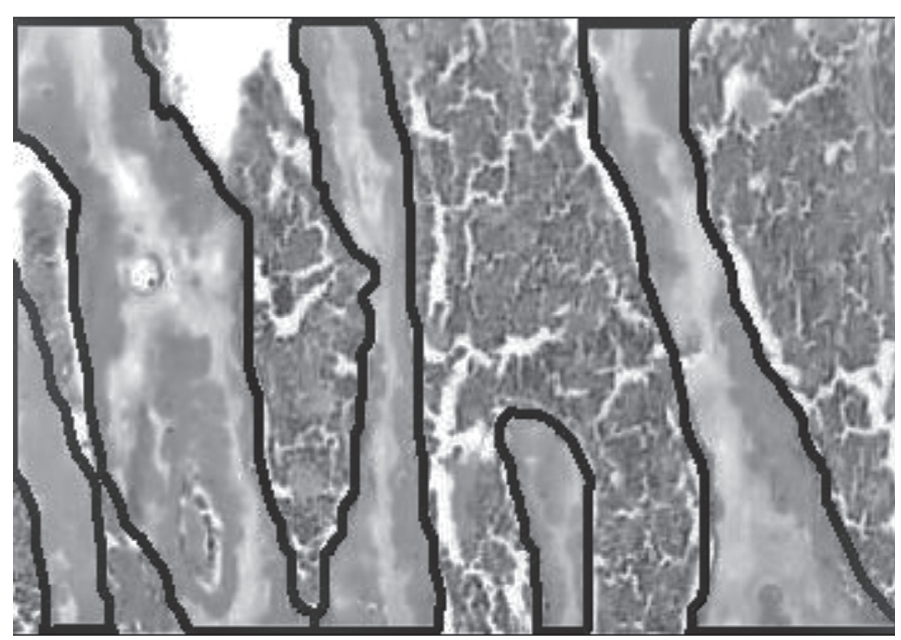

Figura 3 - Aspecto do corte histológico transversal da diáfise tibial (HE, 20X), após delimitação manual do perímetro das trabéculas.

Análise Estatística: foi realizada pela análise de variância (paramétrica ou não-paramétrica), no modelo inteiramente casualizado, complementada com os respectivos testes de comparações múltiplas, utilizando-se, para tanto, os programas SigmaStat ${ }^{\circledR}$ versão 3.5 (Systat Software Inc., 2006) e Minitab ${ }^{\circledR}$ versão 15 (Minitab Inc., 2007). A opção paramétrica (teste " $t$ "de Student e teste de correlação de Pearson) era adotado quando a variável apresentava comportamento gaussiano, caso contrário, indicava-se a opção não-paramétrica (teste $U$ de Mann-Whitney e o teste de Kruskal-Wallis associado ao teste de comparações múltiplas de Dunn). Para todos os cálculos foi utilizado o nível de significância de 5\%.

\section{RESULTADOS}

Análise clínica: no geral, todos os grupos aumentaram a massa corpórea independente da substância administrada sem, contudo, apresentarem diferença significante $(p=0,05)$ (Gráfico 2$)$. O aumento da massa corpórea foi significativamente maior nos animais ooforectomizados $(p=0,005)$ (Gráfico 3).

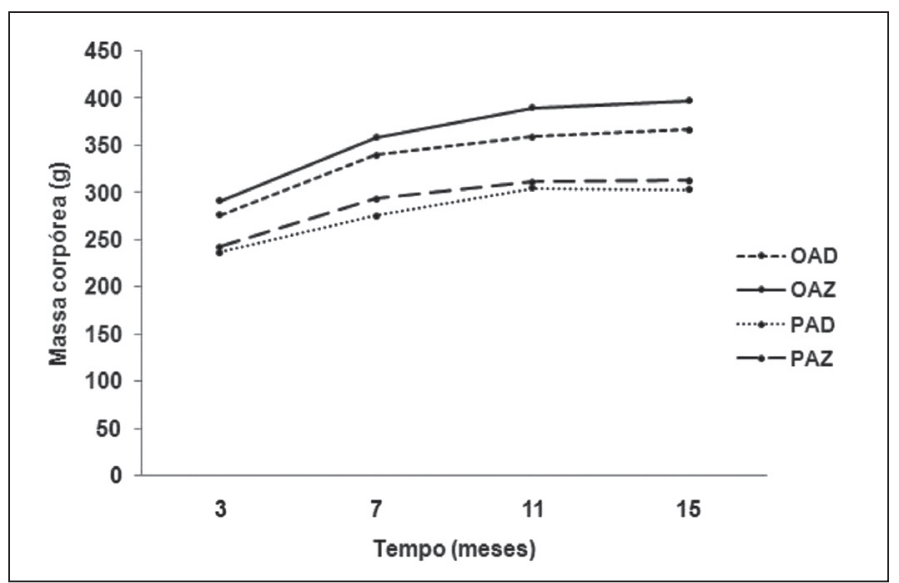

Gráfico 2 - Média da massa corpórea dos grupos ao longo do experimento $(p=0,05)$.

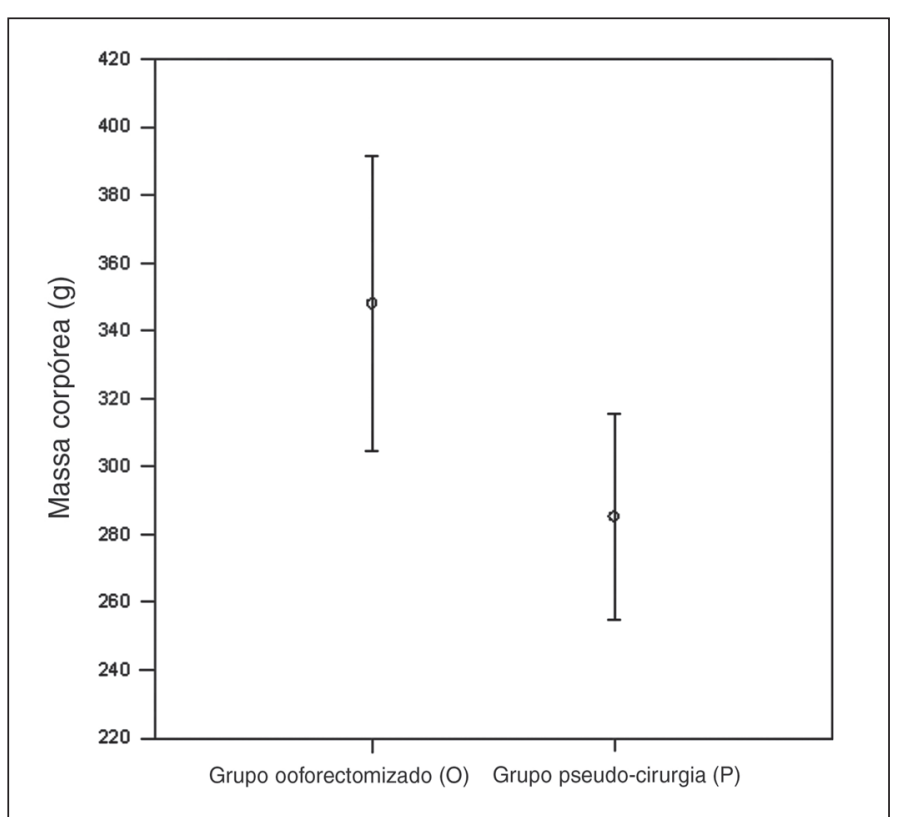

Gráfico 3 - Média da massa corpórea nos grupos "O" e "P" ao longo do experimento $(p=0,005)$.

Levando-se em consideração a substância administrada, verificou-se, dentro do grupo $\mathrm{O}$, que o sub-grupo que recebeu ácido zoledrônico (OAZ) aumentou mais a massa corpórea que o sub-grupo que recebeu água destilada (OAD), não havendo, contudo, diferença estatística $(p=0,47)$ (Gráfico 4). O mesmo se deu em relação ao grupo pseudo-cirurgia $(\mathrm{P})(p=0,68)($ Gráfico 5). 


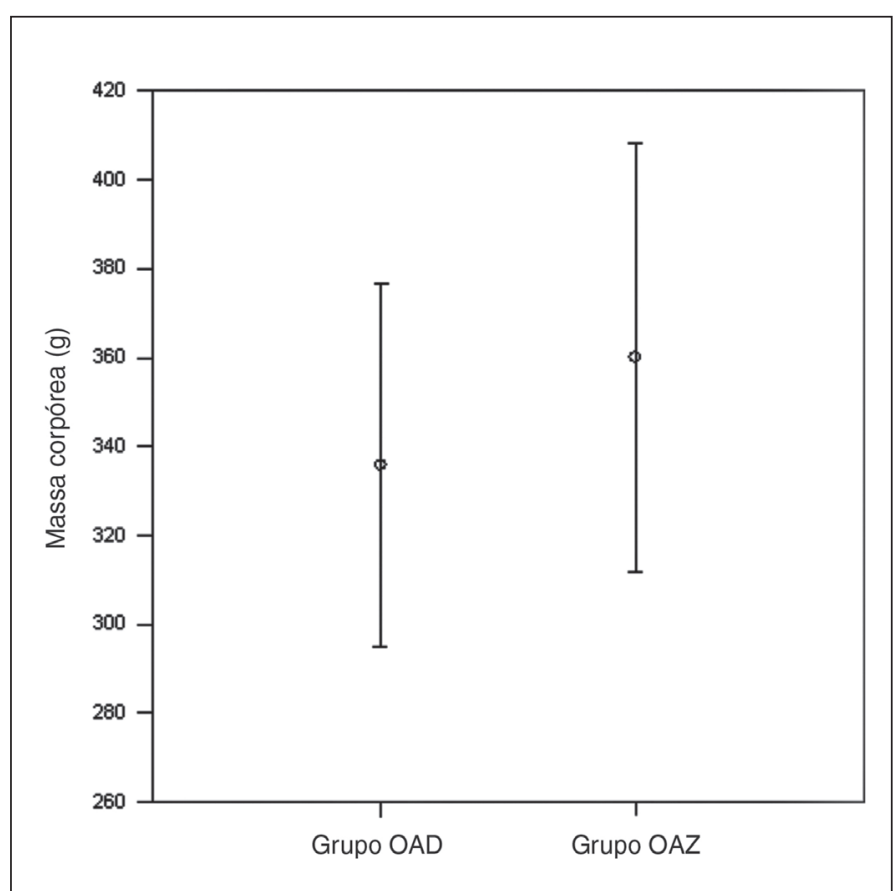

Gráfico 4 - Média da massa corpórea nos grupos OAD e OAZ ao longo do experimento $(p=0,47)$.

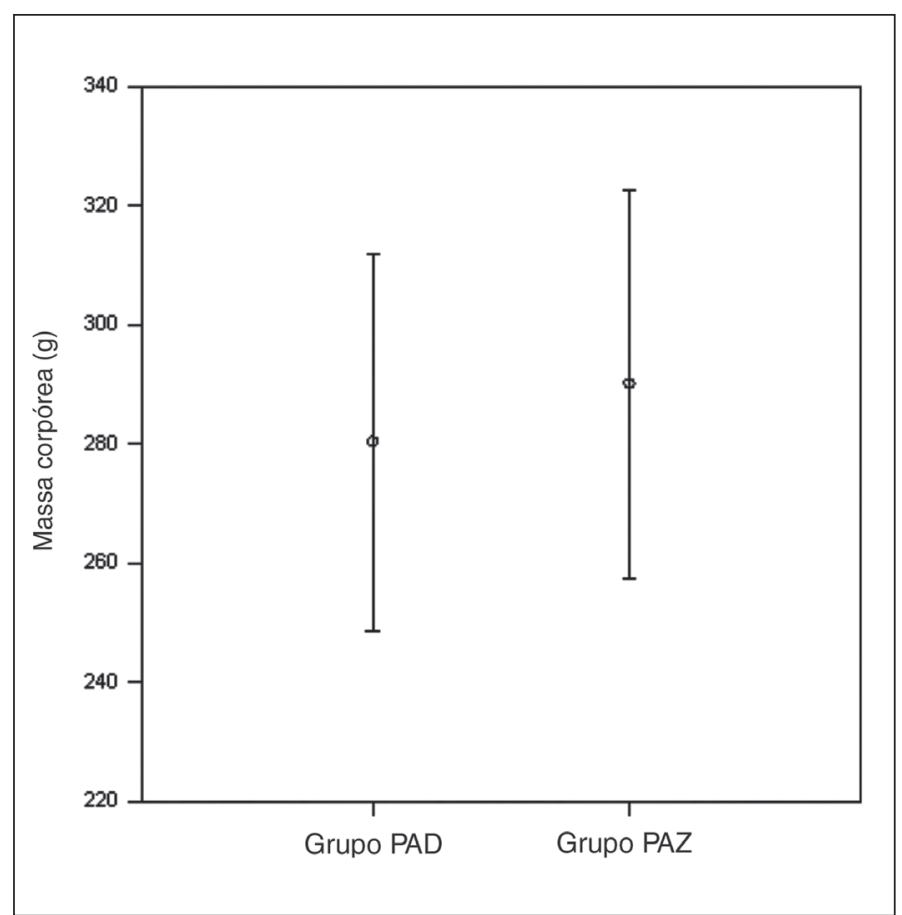

Gráfico 5 - Média da massa corpórea nos grupos PAD e PAZ ao longo do experimento $(p=0,68)$.

Análise biomecânica: quando se compararam todos os quatro grupos, observou-se que aqueles que fizeram uso do ácido zoledrônico suportaram força de compressão maior que os que não o utilizaram, embora sem diferença estatística $(p=0,20)$ (Gráfico 6).

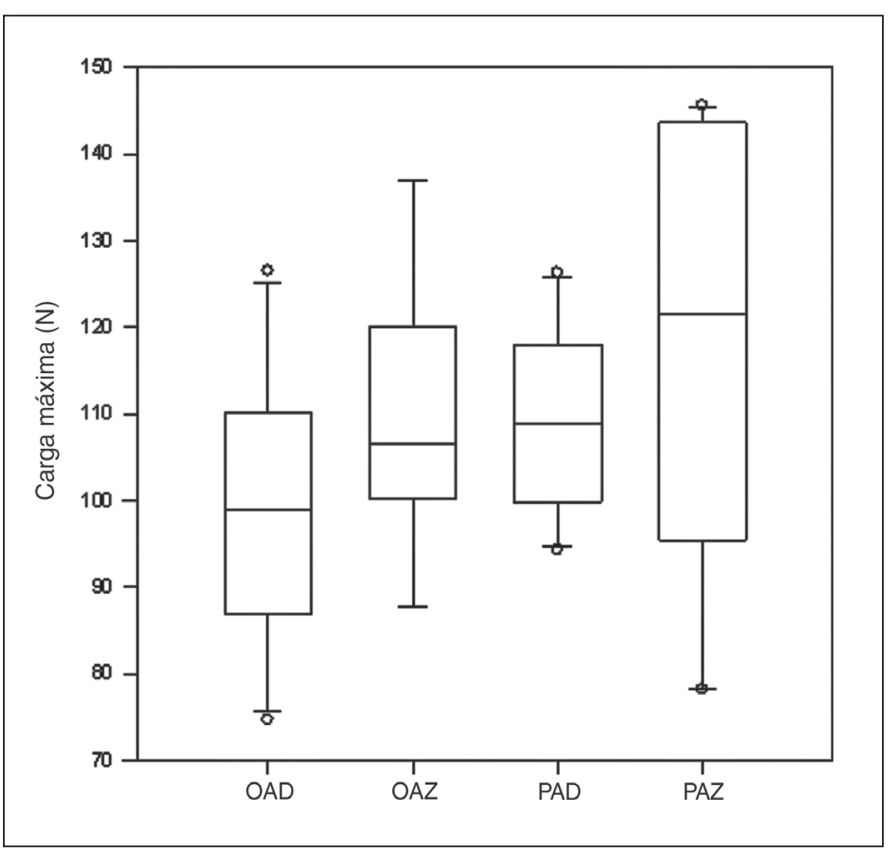

Gráfico 6 - Box plot da mediana de carga máxima no momento da fratura nos diferentes grupos $(p=0,20)$.

A média da carga máxima suportada do grupo OAZ $(109,2 \mathrm{~N} \pm 14,9)$ foi maior que a do grupo OAD $(98,6 \mathrm{~N}$ $\pm 15,4)$, sem diferença estatística entre estes valores $(p=0,14)$ (Gráfico 7). Verifica-se, contudo, que a média da carga máxima suportada pelo grupo OAZ (109,2 $\pm 14,9$ ) foi, estatisticamente, a mesma do grupo PAD $(109,36 \pm 10,2)(p=0,98)$ (Gráfico 8$)$; ao se comparar os grupos $\mathrm{OAD}$ e $\mathrm{PAD}$, verifica-se uma tendência a haver diferença $(p=0,08)$ (Gráfico 9).

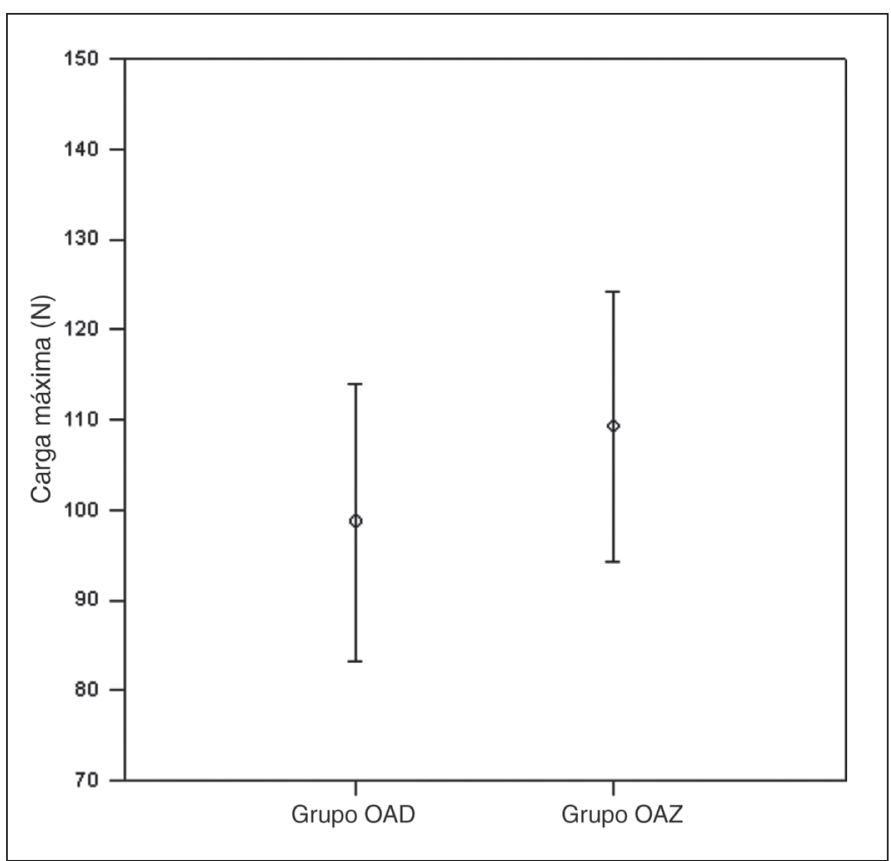

Gráfico 7 - Média da carga máxima no momento da fratura nos grupos OAD e OAZ $(p=0,14)$. 


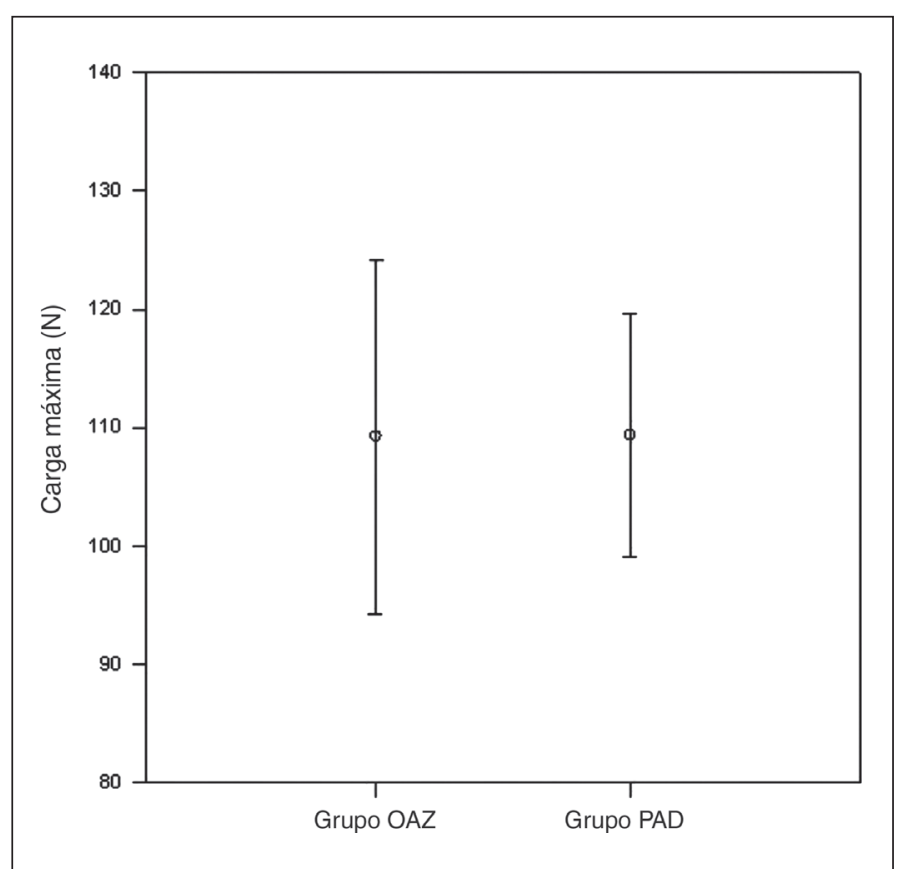

Gráfico 8 - Média da carga máxima no momento da fratura nos grupos OAZ e PAD $(p=0,98)$.

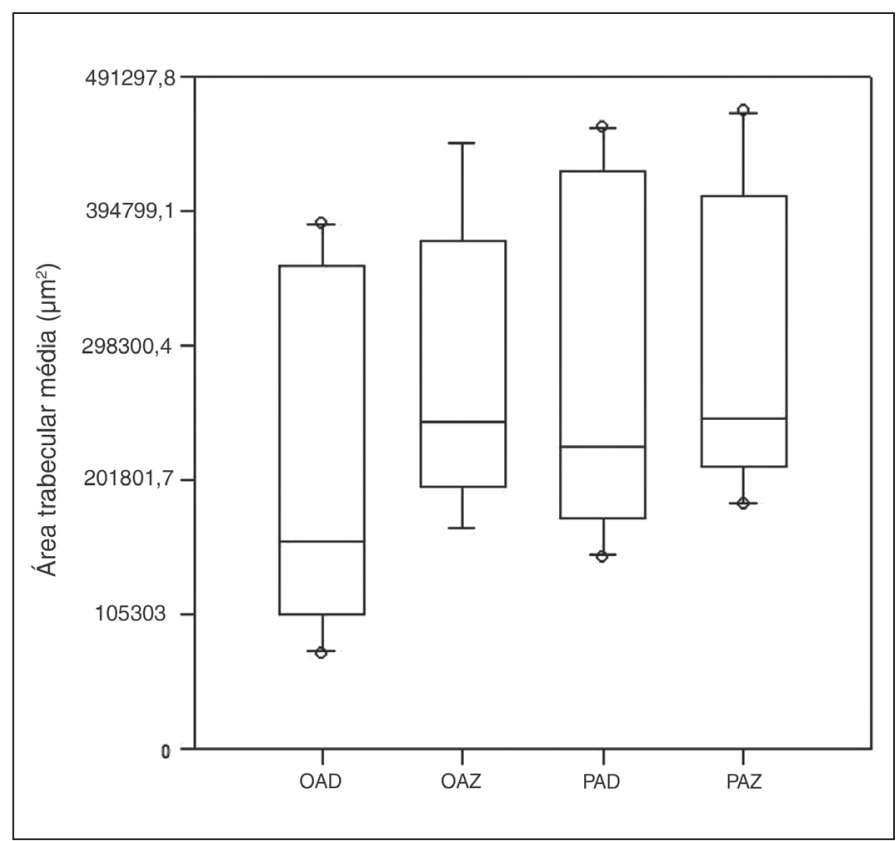

Gráfico 9 - Média da carga máxima no momento da fratura dos grupos OAD e PAD $(p=0,08)$.

Análise histomorfométrica: comparando os quatro grupos, verifica-se o aumento da área óssea trabecular mediana nos grupos que fizeram uso do ácido zoledrônico, ainda que sem significância estatística $(p=0,21)$ (Gráfico 10).

Não houve diferença ao comparar a área trabecular mediana tibial dos grupos OAD $\left(153923,5 \mu \mathrm{m}^{2}\right)$ e OAZ $\left(243002 \mu \mathrm{m}^{2}\right)(p=0,15)$. Porém, verifica-se, que a mediana da área trabecular do grupo OAZ $\left(243002 \mu \mathrm{m}^{2}\right)$ foi, estatisticamente, a mesma do grupo PAD (176189 $\left.\mu \mathrm{m}^{2}\right)(p=0,90)$.

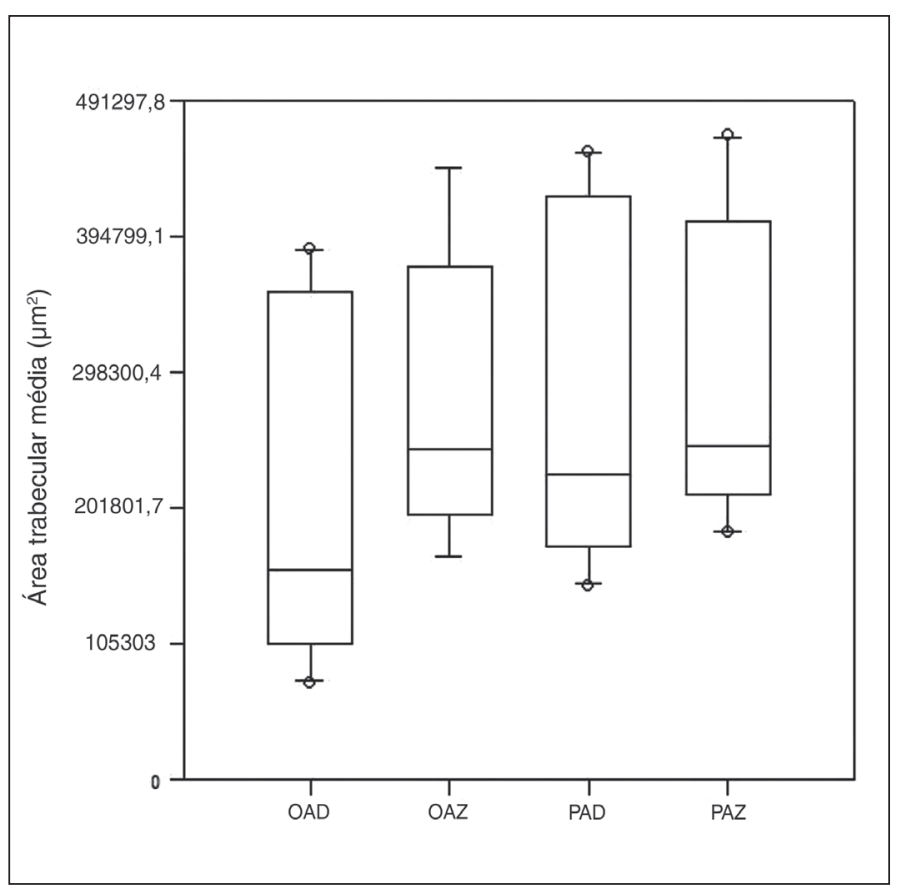

Gráfico 10 - Box plot da mediana da área óssea trabecular nos diferentes grupos $(p=0,21)$.

Análise de regressão linear: feita por meio do coeficiente de Pearson, mostrou haver correlação fortemente positiva entre a área trabecular óssea e a carga máxima suportada pelo corpo de prova $(p=0,04 ; \mathrm{r}=0,95)$ (Gráfico 11).

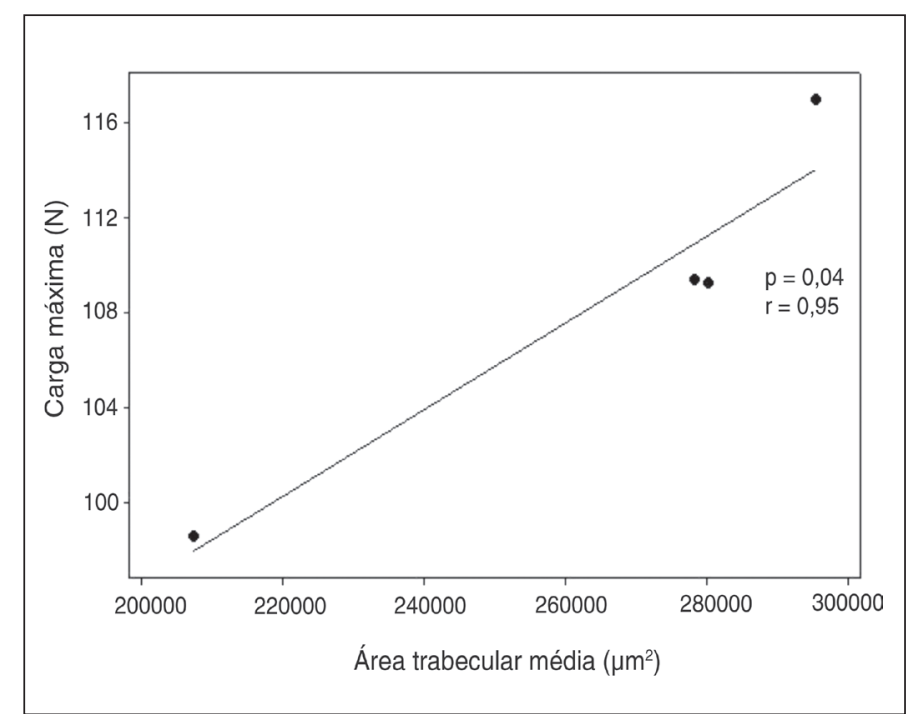

Gráfico 11 - Regressão linear entre a área trabecular óssea e a carga máxima $(p=0,04)$. 


\section{DISCUSSÃO}

O ácido zoledrônico, um novo e poderoso bisfosfonato, age inibindo a ação osteoclástica e, conseqüentemente, diminuindo a reabsorção óssea ${ }^{(10,11)}$. O osso do tipo trabecular é o principal sítio de ação da droga, mantendo a espessura e a densidade das conexões ósseas e aumentando sua resistência às fraturas ${ }^{(12-14)}$. Pacientes com osteoporose, principalmente a primária do tipo I (pós-climatério), que apresentam uma alta atividade osteoclástica, podem beneficiar-se deste bisfosfonato de $3^{\text {a }}$ geração, simplesmente mantendo sua massa óssea trabecular ${ }^{(25)}$.

Para a realização deste estudo, o rato foi escolhido por possuir características próximas às dos seres humanos, no que se refere aos sistemas músculo-esquelético e hormonal, além da facilidade de manuseio, disponibilidade em biotério e baixo custo $^{(26-28)}$.

Em se tratando da massa corporal, os animais com privação de hormônio, ou seja, ooforectomizados (grupo O), apresentaram maior ganho de massa corporal que o grupo pseudo-cirurgia (grupo $\mathrm{P})(p=0,005)$. Achados semelhantes foram obtidos por outros autores $^{(26,29,30)}$. Após o climatério, em função da alteração não apenas da distribuição de tecido adiposo, causado pela deficiência de estrógenos, mas também pelo acúmulo periférico de gordura, ocorre alteração do perfil lipídico e aumento da massa corporal ${ }^{(31)}$. Não verificamos, neste estudo, a influência do ácido zoledrônico no aumento da massa corporal dos animais, fato também comprovado por Reid et $a l^{(16)}$, Hornby et $a l^{(32)}$, Otrock et $a l^{(33)}$ e Gilfillan et $a l^{(34)}$. Conclui-se, portanto, que o aumento da massa corpórea foi causado pela retirada dos ovários (ooforectomia) e não pelas substâncias administradas.

Com relação à análise biomecânica, ao se comparar a carga máxima suportada pelas tíbias nos quatro grupos, observou-se que os grupos que fizeram uso do ácido zoledrônico apresentaram carga maior no momento de fratura, que os que não o utilizaram, embora sem diferença estatística $(p=0,20)$, sugerindo o incremento da massa óssea trabecular naqueles grupos. Tais resultados se repetiram durante a análise dos grupos OAD e OAZ, não havendo diferença significativa entre os grupos $(p=0,14)$, porém, com aumen- to substancial da carga máxima no grupo submetido ao ácido zoledrônico. Sabe-se, atualmente, que a resistência óssea à fraturas deve-se mais à quantidade e qualidade de osso trabecular que a de osso cortical ${ }^{(17)}$. Tal fato poderia justificar os resultados obtidos, uma vez que a tíbia, em sua porção diafisária, possui menor quantidade de osso trabecular proporcionalmente à de osso cortical.

Histomorfometricamente, ao comparar-se a área trabecular óssea nos quatro grupos, pôde-se observar que os grupos que fizeram uso do ácido zoledrônico apresentaram maior área trabecular sem, contudo, significado estatístico $(p=0,21)$. Analisando-se a área trabecular óssea dos grupos ooforectomizados, identificou-se que a presença do ácido zoledrônico não alterou a área trabecular de modo significativo $(p=0,15)$, Contudo, a área trabecular mediana do grupo OAZ foi, estatisticamente, a mesma do grupo $\operatorname{PAD}(p=0,9)$, provando que o ácido zoledrônico teve efeito positivo na manutenção das trabéculas ósseas daquele grupo. Patlas et al analisaram o efeito da ooforectomia na diáfise, metáfise e epífise óssea de ratas, observando a diminuição das trabéculas apenas na região metafisária. Concluíram que a ooforectomia exerce mudanças significativas no osso trabecular de ossos longos, principalmente nas extremidades e, em menor monta, na região média ${ }^{(24)}$.

A análise de dispersão entre a área trabecular óssea e a carga máxima suportada pelo corpo, mostrou que estas são grandezas que se correlacionam positivamente, ou seja, a carga máxima suportada pelo corpo de prova varia, proporcionalmente, à área trabecular do osso. Portanto, a quantidade de trabéculas ósseas pode ser considerada fator preditivo para fraturas decorrentes da osteoporose. Outros estudos se fazem necessários para se evidenciar a eficácia do ácido zoledrônico em outras regiões tibiais.

\section{CONCLUSÃO}

O ácido zoledrônico não teve influência significativa na massa corpórea dos animais. A análise dos resultados mostrou que o ácido zoledrônico não aumentou significativamente a resistência óssea da diáfise tibial ou a área trabecular óssea diafisária. 


\section{REFERÊNCIAS}

1. IBGE - Instituto Brasileiro de Geografia e Estatística. Projeção preliminar da população do Brasil por sexo e idades simples: 19802050 - Revisão 2000. IBGE; 2000.

2. IBGE - Instituto Brasileiro de Geografia e Estatística. Projeção da população do Brasil por sexo e idade para o período de 1980-2050 - Revisão 2004 metodologias e resultados. Estimativas anuais e mensais da população do Brasil e das unidades da federação: 1980-2020 - Metodologia. Estimativas das populações municipais - Metodologia. IBGE 2004. p.1-82.

3. OMS/WHO - World Health Organization. World health statistics 2006. [Nonserial publication]. Geneva: WHO Press; 2006. p. 21-23.

4. Nguyen TV, Blangero J, Eisman JA. Genetic epidemiological approaches to the search for osteoporosis genes. J Bone Miner Res. 2000;15:392-401.

5. Pinto Neto AM, Soares A, Urbanetz AA, Souza ACA, Ferrari AEM, Amaral B, et al. Consenso brasileiro de osteoporose 2002. Rev Bras Reumatol. 2002;42(6):343-54.

6. NIH Consensus Development Panel on Osteoporosis Prevention, Diagnosis, and Therapy. Osteoporosis prevention, diagnosis, and therapy. JAMA. 2001;285:785-95.

7. Notelovitz M. Osteoporose: prevenção, diagnóstico e conduta. Rio de Janeiro: EPUC; 2001.

8. Leite MOR. Tratamento da osteoporose pós-menopausa. Arq Bras Endocrinol Metab. 1999; 43(6):442-5.

9. Guarniero R, Oliveira LG. Osteoporose: atualização no diagnóstico e princípios básicos para o tratamento. Rev Bras Ortop. 2004;39(9):477-85.

10. Amanat N, Brown R, Bilston LE, Little DG. A single systemic dose of pamidronate improves bone mineral content and accelerates restoration of strength in a rat model of fracture repair. J Orthop Res. 2005;23:1029-34.

11. Dunford JE, Thompson K, Coxon FP, Luckman SP, Hahn FM, Poulter $C D$, et al. Structure-activity relationships for inhibition of farnesyl diphosphate synthase in vitro and inhibition of bone resorption in vitro by nitrogen-containing bisphosphonates. J Pharmacol Exp Ther. 2001;296(2):235-42.

12. Walter C, Grötz KA, Kunkel M, Al-Nawas B. Prevalence of bisphosphonate associated osteonecrosis of the jaw within the field of osteonecrosis. Support Care Câncer. 2007;15(2):197-202.

13. Griz L, Colares V, Bandeira F. Tratamento da doença de Paget óssea: importância do ácido zoledrônico. Arq Bras Endocrinol Metab. 2006;50(5):845-51.

14. Fernandes C, Leite RS, Lanças FM. Bisfosfonatos: síntese, análises químicas e aplicações farmacológicas. Quim Nova. 2005;28(2):274-80.

15. Perifanis V, Vyzantiadis T, Tziomalos K, Vakalopoulou S, Garipidou $\mathrm{V}$, Athanassiou-Metaxa $\mathrm{M}$, et al. Effect of zoledronic acid on markers of bone turnover and mineral density in osteoporotic patients with beta-thalassaemia. Ann Hematol. 2007;86(1):23-30.

16. Reid IR, Brown J, Burckhardt P, Horowitz Z, Richardson P, Trechel U, et al. Intravenous zoledronic acid in postmenopausal women with low bone mineral density. N Engl J Med. 2002; 346(9):653-61.

17. Matos MA, Araújo FP, Paixão FB. Os efeitos do zoledronato na remodelação óssea durante o processo de reparação. Acta Cir Bras. 2007;22(2):115-9.
18. Shapiro J, Smith B, Beck T, Ballard P, Dapthary M, BrintzenhofeSzoc $\mathrm{K}$, et al. Treatment with zoledronic acid ameliorates negative geometric changes in the proximal femur following acute spinal cord injury. Calcif Tissue Int. 2007;80(5):316-22.

19. Wise LM, Waldman SD, Kasra M, Cheung R, Binnington A, Kandel RA, et al. Effect of zoledronate on bone quality in the treatment of aseptic loosening of hip arthroplasty in the dog. Calcif Tissue Int. 2005;77:367-75.

20. Amanat N, McDonald M, Godfrey C, Bilston L, Little D. Optimal timing of a single dose of zoledronic acid to increase strength in rat fracture repair. J Bone Miner Res. 2007;22(6):867-76.

21. Smith BA, Livesay GA, Woo SLY. Biology and biomechanics of the anterior cruciate ligament. Clin Sports Med. 1993;12:637-70.

22. Smith EL, Raab DM. Osteoporosis and physical activity. Acta Med Scand Suppl. 1986; 711:149-56.

23. Junqueira LC, Carneiro J. Histologia básica. 8a ed. Rio de Janeiro: Guanabara-Koogan; 1995.

24. Patlas N, Zadik Y, Yaffe P, Schwartz Z, Ornoy A. Oophorectomy-induced osteopenia in rats in relation to age and time postoophorectomy. Cells Tissues Organs. 2000;166:267-74.

25. Riggs BL, Melton LJ 3rd. Involutional osteoporosis. N Engl J Med. 1986;314:1676-86.

26. Marques KP, Taveira LAA. Avaliação microscópica das estruturas periodontais e morfologia óssea alveolar em ratas ovariectomizadas. Rev Fac Odontol Bauru. 1998;6:9-18.

27. Huang TH, Lin SC, Chang FL, Hsieh SS, Liu SH, Yang RS. Effects of different exercise modes on mineralization, structure, and biomechanical properties of growing bone. J Appl Physiol. 2003;95(1):300- 7.

28. Paz LHBC, Jorgetti V, Yoshinari NH. Modelos animais de osteoporose. Rev Hosp Clin Fac Med Univ São Paulo. 1997; 52(2):86-9.

29. Carvalho DCL, Cliquet Junior A. Ação do ultra-som de baixa intensidade sobre ossos de ratas osteopênicas. Acta Ortop Bras. 2003;11(1):17- 24.

30. Cardoso Netto C, Franco M, Cunha MSCA, Myiasaka CK. Efeitos da ovariectomia experimental no metabolismo ósseo de ratas Wistar adultas: um modelo para estudo da osteoporose. Rev Cienc Med Biol. 2006;5(3):231-8

31. Dias R, Luca LA, Ramos MD, Antonini Filho R, Rudge MVC. Avaliação da atividade estrogênica após a menopausa. J Bras Ginecol. 1982;92:261- 9.

32. Hornby SB, Evans GP, Hornby SL, Pataki A, Glatt M, Green JR Long-term zoledronic acid treatment increases bone structure and mechanical strength of long bones of ovariectomized adults rats. Calcif Tissue Int. 2003;72:519-27.

33. Otrock ZK, Azar ST, Shamseddeen WA, Habr D, Inati A, Koussa $\mathrm{S}$, et al. Intravenous zoledronic acid treatment in thalassemiainduced osteoporosis: results of a phase II clinical trial. Ann Hematol. 2006;85:605-9.

34. Gilfillan CP, Strauss BJS, Rodda CP, Bowden DK, Kean AM, Obaid $\mathrm{M}$, et al. A randomized, double-blind, placebo-controlled trial of intravenous zoledronic acid in the treatment of thalassemia-associated osteopenia. Calcif Tissue Int. 2006;79:138-44. 